\title{
ANÁLISE JURÍDICA DO DESENVOLVIMENTO CONSTITUCIONAL COM ENFOQUE NO POVO INDÍGENA TAPEBA $^{1}$
}

LEGAL ANALYSIS OF CONSTITUTIONAL DEVELOPMENT WITH A FOCUS ON THE TAPEBA

INDIGENOUS PEOPLE

Tiê Tófoli de OLIVEIRA ${ }^{2}$

Renato Luís MELO FILHO

ISSUE DOI: $10.21207 / 2675-0104.2019 .939$

\section{RESUMO}

O presente trabalho tem por escopo apresentar a situação atual do povo indígena Tapeba, apresentando todo o processo histórico que eles passaram desde os tempos da colonização, o trabalho irá contar também com uma recapitulação jurídica e constitucional demonstrando todos os avanços constitucionais em direito indigenista feitos por cada uma delas, demonstrando assim todas as

\footnotetext{
${ }^{1} \mathrm{O}$ presente artigo sintetiza a monografia de conclusão da pesquisa, realizada para o Programa Interno de Bolsas de Iniciação Científica (PIBIC 2018-2019) da Faculdade de Direito de Franca (FDF), Franca/SP.

${ }^{2}$ Discente da Faculdade de Direito de Franca (FDF), Franca/SP. Bolsista do Programa Interno de Bolsas de Iniciação Científica (PIBIC 2018-2019).

${ }^{3}$ Mestre em Direito Público (Direito Processual Civil-Direito Constitucional) pela UNESP Universidade Estadual Paulista Júlio de Mesquita Filho (2015). Graduado em Direito pela UNESP Universidade Estadual Paulista Júlio de Mesquita Filho (2011). Advogado (desde 2012). Professor Substituto de Direito Processual Civil da UNESP - Universidade Estadual Paulista Júlio de Mesquita Filho (desde 2016). Professor da Faculdade de Ensino São Luís de Jaboticabal (desde 2016). Coordenador (2017) e Professor (desde 2016) da Escola Superior de Advocacia (ESA) - Núcleo Franca, onde ministrou o curso "Aprenda a Trabalhar com o Novo CPC" ( $1^{\circ}$ semestre/2016). Professor Substituto e Colaborador da Faculdade de Direito de Franca (FDF), onde orienta Pesquisas de Iniciação Científica, Trabalhos de Conclusão de Curso (desde 2015)
} 
irregularidades sejam elas constitucionais ou da lei comum. Este trabalho conta com a análise documentos como processos jurídicos, Constituição Federal, leis, Relatório Circunstanciado de Identificação e Delimitação da Terra Indígena além de contar com documentos históricos, este trabalho serve uma função de denúncia de irregularidades e inconstitucionalidades cometidas pelo sistema jurídico brasileiro a povos indígenas com um foco maior no povo indígena Tapeba, situado no município de Caucaia-CE. A proposta é movimentar informações e gerar debate dentro do ambiente jurídico para que as injustiças cometidas contra o povo Tapeba nunca se repitam e para lembrar que os direitos humanos se aplicam a todos.

Palavras-chave: Tapeba, Constituição, Demarcação de Terras Indígenas.

\section{ABSTRACT}

The present paper aims to present the current situation of the Tapeba indigenous people, presenting the entire historical process that they have undergone since the times of colonization. each of them, thus demonstrating all irregularities, whether constitutional or common law. This work relies on the analysis of documents such as legal processes, the Federal Constitution, laws, a Detailed Report on the Identification and Delimitation of the Indigenous Land, in addition to having historical documents, this work serves as a function of denouncing irregularities and unconstitutionalities committed by the Brazilian legal system to peoples. with a greater focus on the Tapeba indigenous people, located in the municipality of Caucaia-CE. The proposal is to move information and generate debate within the legal environment so that the injustices committed against the Tapeba people are never repeated and to remember that human rights apply to everyone.

Keywords: Tapeba, Constitution, Demarcation of Indigenous Lands.

\section{INTRODUÇÃO}

Atualmente o povo Tapeba encontra-se dividido em 12 aldeias, todas dentro da área demarcada pelo Relatório Circunstanciado de Identificação e Delimitação da Terra Indígena (RECID) de 2013, localizadas na região de Caucaia distrito do município de Fortaleza: Sobradinho; Ponte; Capoeira; Trilho; Jandaiguaba; Capuan, Jardim do Amor, Aldeia dos Cacos (Coité); Lagoa I; Lagoa II, Lameirão e Lagoa das Bestas. A área declarada é de 5,2 mil hectares, o que equivale a 4,31\% do território total do município. De acordo com o último censo (2014), a população indígena se encontra com cerca de 6651 índios.

Atualmente eles têm sua área declarada pelo estado brasileiro e aguardam a FUNAI (Fundação Nacional do Índio) fazer a licitação para executar a demarcação física da terra. Vale ressaltar que mediante a atual política do Governo Federal a FUNAI vem sofrendo constante processo de sucateamento. Neste momento o povo Tapeba aguarda a mobilização desta fundação para que o seu território seja devidamente demarcado conforme decreto $n^{\circ} 1775 / 96$. Processo que já dura mais de 30 anos, o que vai contra o disposto no artigo $\mathrm{n}^{\circ} 67$ da constituição federal de 1988. 


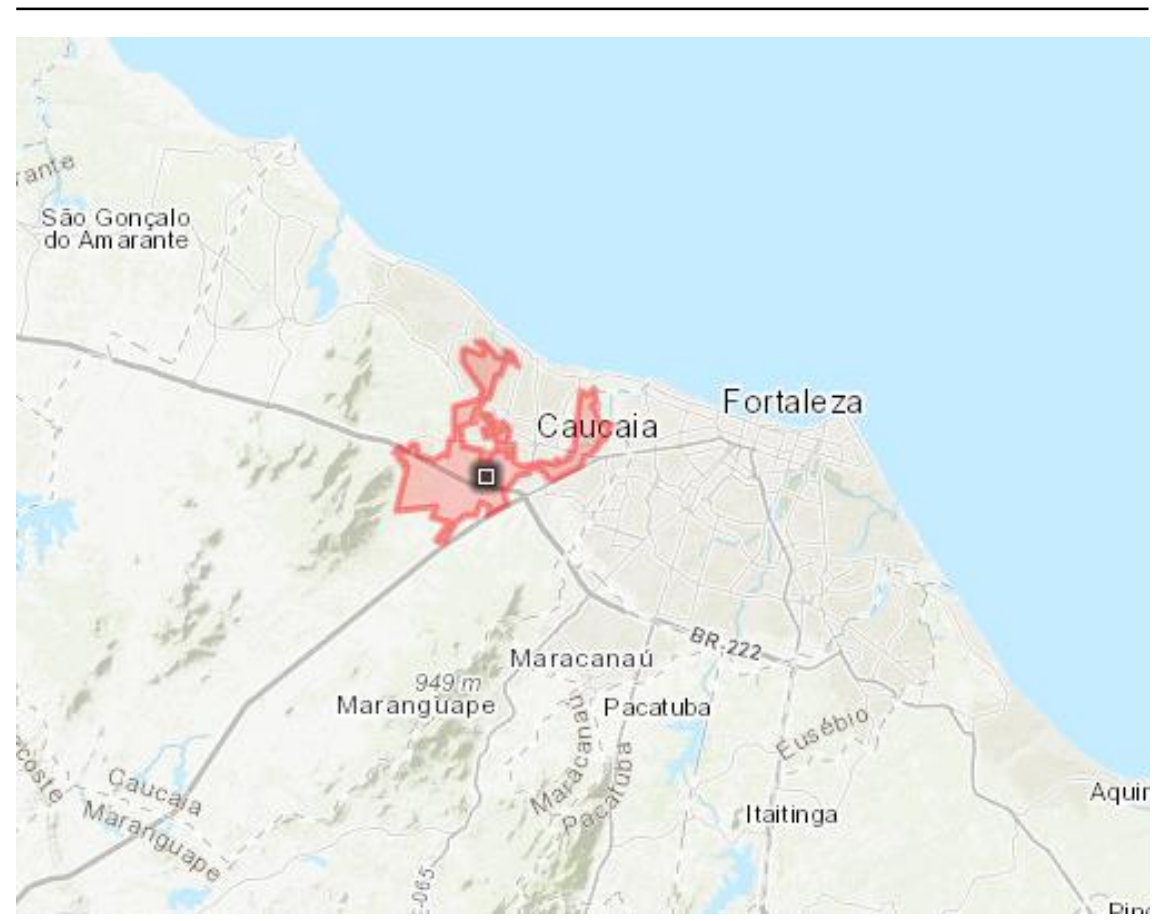

Mapa da Terra Indígena Tapeba, declarada pelo ministro da justiça em 4 de novembro de 2017. Acessado em <https://terrasindigenas.org.br/pt-br/terras-indigenas/3864> em 07 de Set.

Pelas aldeias Tapeba estarem distribuídas próximas à região metropolitana de Fortaleza, sofrem com o constante avanço de construção desordenada de casas populares, comuns nas periferias dos grandes centros urbanos e são impactados por diversas obras de infraestrutura, além de estarem sujeitos a tipos de violências ligados a vida nas grandes cidades.

É importante salientar que o povo Tapeba só foi reconhecido como povo indígena novamente pela FUNAI na década de 1980. Isto se dá por conta do processo histórico de negação étnica que os colonizadores impuseram aos povos colonizados. Devido a este processo de negação étnica uma das maiores conquistas do povo Tapeba foi a quebra do tabu de ser "índio", pois um dos principais obstáculos do povo Tapeba foi a aceitação do termo que na região vem sempre com o sentido pejorativo, o próprio termo "Tapeba" foi utilizado por séculos no sentido prejudicial. 
Isso explica o processo de crescimento populacional para além da natalidade que pode ser visto no gráfico a seguir:

Dados Demográficos da Terra Indigena

\subsection{0}

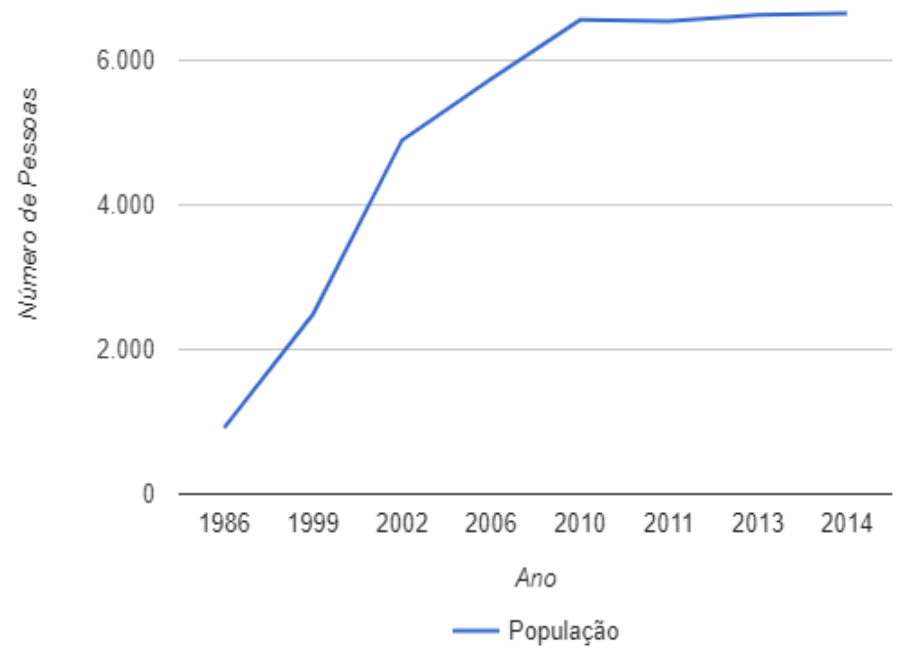

Crescimento populacional de 1985 até 2014. Acessado em 07 de Set. <https://terrasindigenas.org.br/pt-br/terras-indigenas/3864>

\section{PROCESSO DEMARCATÓRIO}

O processo demarcatório é regulamentado pelo estatuto do índio (Lei 6001/73) e decreto $n^{\circ} 1775 / 96$ que consistem no meio administrativo para delimitar e identificar o território tradicionalmente ocupado por povos indígenas, o decreto é de suma importância para a regulamentação segue os artigos:

O processo em si possui nove (9) etapas: 


\subsection{ESTUDOS DE IDENTIFICAÇÃO E DELIMITAÇÃO, A CARGO DA FUNAI;}

O início do processo de demarcação se dá através da identificação e delimitação da área o trabalho é realizado por um grupo técnico de trabalho (GT) composto por antropólogo de qualificação reconhecida que elaborará o estudo antropológico de identificação, além dos estudos antropológicos serão conduzidos também estudos complementares de natureza etno-histórica, sociológica, jurídica, cartográfica, ambiental e o levantamento fundiário necessários à delimitação.

Contraditório administrativo - Após a conclusão a conclusão do trabalho de identificação e delimitação o grupo técnico (GT) irá apresentar o Relatório Circunstanciado de Identificação e Delimitação (RECID) da Terra Indígena ao órgão federal de assistência ao índio, demonstrando a terra indígena a ser demarcada, com a publicação deste relatório terceiros assim como o estado e o município podem adentrar o processo demarcatório assim como apresentar contestação dentro do prazo de até 90 dias após a publicação do relatório.

Declaração dos limites, a cargo do Ministro da Justiça - Após os trâmites o documento é encaminhado ao ministro do estado e da justiça, que poderá declarar, mediante portaria, os limites da terra indígena e determinar sua demarcação, prescrever diligências que entender necessárias ou ainda desaprovar o estudo que será devolvido ao órgão federal de assistência ao índio.

Demarcação física, a cargo da Funai;

Levantamento fundiário de avaliação de benfeitorias implementadas pelos ocupantes não-índios, a cargo da Funai, realizado em conjunto com o cadastro dos ocupantes não-índios, a cargo do Incra. $\mathrm{O}$ INCRA fica encarregado de fazer o levantamento de todos os não-índios que vivem na área demarcada.

Homologação da demarcação, a cargo da Presidência da República. Mediante decreto o Presidente da República faz a homologação da área.

Retirada de ocupantes não-índios, com pagamento de benfeitorias consideradas de boa-fé, a cargo da Funai, e reassentamento dos ocupantes não-índios que atendem ao perfil da reforma, a cargo do Incra. A FUNAI se encarrega da retirada e do pagamento das benfeitorias enquanto o Incra fica encarregado de fazer o reassentamento dos nãoíndios. 
Registro das terras indígenas na Secretaria de Patrimônio da União, a cargo da Funai;

Interdição de áreas para a proteção de povos indígenas isolados, a cargo da Funai.

Vale ressaltar que o processo de demarcação tem caráter apenas declaratório, tendo em vista que que este é um direito preexistente que é apenas previsto e assegurado pela constituição.

\section{CASO ESPECÍFICO DE DEMARCAÇÃO DE TERRAS TAPEBA}

O caso Tapeba passou por 3 tentativas de demarcação antes de ser aceito os primeiros 2 anulados pelo mesmo motivo o não cumprimento do mandado de segurança $\mathrm{n}^{\circ} 5.505 \mathrm{e}$ fez "anular as tentativas de demarcação, e que criou o grupo de trabalho para os fins indicados, bem como os atos subsequentes, por não ter sido incluído, no referido grupo, um representante do município reclamante", nota-se que este não é um dos pré requisitos dispostos no decreto $\mathrm{n}^{\circ} 1775 / 96$, em todas as vezes o processo foi movido pela mesma parte a família Arruda. Com a terceira tentativa a mesma ação foi movida contra o processo demarcatório, porém desta vez foi proposto um acordo firmado pela Comunidade Indígena Tapeba União Federal, estado do Ceará, FUNAI, Procuradoria Geral do Estado do Ceará, Advocacia Geral da União, secretaria estadual do meio ambiente do Ceará, prefeitura municipal de caucaia e os representantes da família Arruda, através do processo judicial $\mathrm{n}^{\circ} 080056-17.2013 .4 .05 .8100$, faz com que os Tapebas abram mão de parte do seu território ao mesmo tempo que a família Arruda desista das ações em que se discute a nulidade do processo de demarcação de terras indígenas. Este acordo acaba por beneficiar mais a família Arruda, porém o povo Tapeba acaba optando por ele, pela iminência da nova anulação judicial, e também por conta das diversas situações de violências que decorrem a décadas como por exemplo o assassinato de líderes Tapeba ou ameaças de morte, fora a violência institucional e fundiária sofrida por eles.

No entanto, mesmo após este acordo homologado em 19 de abril de 2016 a demarcação da TI Tapeba ainda não foi concluída, o ministro da justiça possuía o prazo de 30 dias para expedir a portaria declaratória que foi recebida no dia 21 de novembro de 2016 e só foi publicada no dia 4 de setembro de 2017, 287 dias entre a entrega e a assinatura, porém após isto 
o processo de demarcação de terras indígenas Tapeba está paralisado esperando, aguardando a FUNAI fazer a licitação para executar a demarcação física da terra. Colocar os marcos geodésicos etc. No momento está demarcada só no papel. Isso ainda não tem previsão oficial para ocorrer (muito em virtude da crise que passa o órgão, uma vez que não definição do novo governo a qual ministério a FUNAI íntegra, antes era o da justiça, está causando uma desestruturação orçamentária do órgão).

Esta demora na demarcação traz diversos prejuízos ao povo Tapeba, tendo em vista que o judiciário brasileiro é um dos principais responsáveis pela sistemática violação dos direitos a propriedade dos povos originários, pois só os povos Tapebas em si tem 13 ações judiciais em curso além de outras 17 arquivadas isto até a data de 14 de julho 2017. Entre elas ações da justiça estadual que apesar de incompetente para tratar de matéria já proferiu diversas decisões, como por exemplo duas ordens de despejo, pode ser visto isto também em decisão proferida no processo ${ }^{\circ} 0814836$ 54.2016.4.05.8100 $8^{\mathrm{a}}$ vara Federal depois retratado:

Estarte não há, na região referenciada, demarcação de terras públicas tradicionalmente ocupadas pelos índios. Quando muito deve haver alguns estudos prévios para a demarcação previstos no Decreto $\mathrm{n}^{\circ} 1.775 / 96$. O que há de concreto no mundo jurídico que atine ao tema são os títulos de propriedade dos proprietários de glebas na região urbana e rural do Município de Caucaia (vide matrícula que instruiu a inicial).

Não existe, até onde sei, nenhum documento público que denota que a área em que se encrava o terreno do requerente seria de domínio público (aforamento, ocupação, etc.) da União ou de qualquer entidade de direito público. Em suma se está diante de duas questões constitucionalmente normatizadas: o direito a usar, gozar e dispor da propriedade privada, desde que não afronte as limitações administrativas (nelas contidas as limitações urbanísticas) e um suposto direito de posse permanente de terras tradicionalmente ocupadas pelos "índios Tapebas" do Município de Caucaia. No entanto há uma diferença fundamental no caso em exame: o título de propriedade do autor faz presunção jure et de jure de que ele é o proprietário do terreno referenciado na multa impugnada, não havendo uma só prova jurídica de que aquela terra seja da União e tradicionalmente ocupada por população indígena. É evidente que se for posteriormente realizada a correspondente demarcação e nela for incluído o terreno do autor, e nessa condição ele for elencado na SPU como terra da União, a presunção jure et de jure atual do título de propriedade do autor perderá força jurídica.

Pelas razões acima só me resta conhecer e dar provimento aos embargos de declaração interpostos para o efeito de suspender os 
efeitos jurídicos do termo de embargo $\mathrm{n}^{\circ} 11453$ lavrado pelo IBAMA em desfavor do autor. (CUNHA PORTO, 09/02/2017.) ${ }^{4}$

Logo no mesmo passo que o processo de demarcação está sendo lento o contrário pode ser visto quando o assunto se trata de não-indígenas querendo assegurar supostos direitos sobre o território tapeba ou ainda a expulsão deste povo indígena de sua terra ancestral, esta preferência a nãoindígenas pela justiça brasileira pode ser vista em diversas ocasiões como por exemplo a anulação judicial de dois procedimentos de demarcação além da renúncia que teve que ser feita por parte dos Tapeba para que a terceira não fosse anulada, é assim que o povo Tapeba vive com muita luta e sofrimento apenas para garantir que sua terra seja demarcada direito assegurado a eles pela própria constituição.

\section{$4 \quad$ DENÚNCIA AO CIDH}

Diante tamanha lentidão e a recorrente perda de território e recursos naturais o povo Tapeba recorre constantemente aos meio legais (mesmo que tenham poucas vitórias neste meio) um excelente exemplo disto é a Denúncia do Estado Brasileiro por Violação ao Direito de Propriedade Coletiva do Povo Tapeba, a comissão interamericana de direitos humanos (CIDH) no qual só cabe ação quando se encerra todos os meios legais de um país, portanto a denúncia diz respeito ao artigo 21 da convenção americana de direitos humanos:

1. Toda pessoa tem direito ao uso e gozo dos seus bens. A lei pode subordinar esse uso e gozo ao interesse social.

2. Nenhuma pessoa pode ser privada de seus bens, salvo mediante o pagamento de indenização justa, por motivo de utilidade pública ou de interesse social e nos casos e na forma estabelecidos pela lei.

3. Tanto a usura como qualquer outra forma de exploração do homem pelo homem devem ser reprimidas pela lei. (CIDH, 1969, ART.21) ${ }^{5}$

5 Comissão Interamericana de Direitos Humanos, CONVENÇÃo AMERICANA SOBRE

DIREITOS HUMANOS, 22 de novembro de 1969, pode ser encontrado em <https://www.cidh.oas.org/basicos/portugues/c.convencao_americana.htm> 
Esta denúncia possui dois objetivos o primeiro é chamar a responsabilidade mundial ao brasil, e a segunda é criar um fato político. Sobre o fato político a proposta é apresentar ao mundo o caso Tapeba que é um caso emblemático de violação de direitos humanos, pela grande demora do estado e a preferência por agilidade em ações de não-indígenas sobre a terra atualmente delimitada. $\mathrm{O}$ primeiro ponto que trata de chamar a responsabilidade mundial ao brasil segue em curso, porém ainda não conseguiu ser discutido pela Corte Interamericana que é quem trata das denúncias recebidas pela CIDH seguindo o mesmo modelo da Corte Europeia de Direitos Humanos. É importante ressaltar que a situação atual do povo Tapeba também vai contra o artigo $\mathrm{n}^{\circ} 8.1$ que garante o disposto a seguir:

Toda pessoa tem direito a ser ouvida, com as devidas garantias e dentro de um prazo razoável, por um juiz ou tribunal competente, independente e imparcial, estabelecido anteriormente por lei, na apuração de qualquer acusação penal formulada contra ela, ou para que se determinem seus direitos ou obrigações de natureza civil, trabalhista, fiscal ou de qualquer outra natureza. (CIDH, 1969, ART.8,1. $)^{6}$

Sobre prazos razoáveis a corte entendeu que no caso Yakye Axa vs Paraguai 11 anos e 8 meses nao poderia ser considerado um prazo razoável, logo os 30 anos de processo demarcatório da TI Tapeba pode ser apenas considerado uma ofensa direta aos direitos humanos.

\section{CONSIDERAÇÕES FINAIS}

Com a promulgação da constituição de 1988 surgiu uma nova gama de direitos e garantias aos povos indígenas, como a garantia da demarcação de suas terras e o direito à saúde e educação diferenciada. Porém como pode ser visto ao longo deste trabalho nem sempre elas são cumpridas, a saúde e educação diferenciada os Tapeba lograram conquistas em suas reivindicações, já no que toca a regularização fundiária o caso Tapeba é um caso emblemático, principalmente no aspecto jurídico, uma vez que a demarcação de terras foi barrada neste âmbito duas vezes, e decorre a 30 anos, e só não teve o processo anulado novamente, pela terceira vez, graças ao acordo feito com a família Arruda. Este acordo 
claramente beneficia os Arruda, no entanto, pela iminência do terceiro cancelamento o povo Tapeba acabou optando por aceitar o acordo e abrir mão de parte do seu território, este que já estava regularizado no RECID de 2013. E ainda hoje enfrenta uma série de processos e ações visando paralisar a demarcação da terra indígena Tapeba

$\mathrm{O}$ âmbito jurídico brasileiro tem a tendência a sempre pender ao lado dos não-índios, analisando apenas o caso do povo Tapeba é possível ver estas diversas irregularidades um exemplo disso é a justiça estadual estar julgando ações na qual as partes são povos indígenas o que é vedado pelo artigo $\mathrm{n}^{\circ} 109$ parágrafo XI da constituição federal que garante a competência de julgar a disputa sobre direitos indígenas a justiça federal. Outro ponto é a lentidão no andamento do processo demarcatório que passou 257 dias do prazo estabelecido pelo acordo para ser assinado pelo ministro da justiça, e com o sucateamento da FUNAI os procedimentos para a demarcação física da área encontra-se paralisado.

Todos estes fatores geraram a denúncia a comissão interamericana de direitos humanos (CIDH) pedindo a responsabilidade mundial ao Brasil, no entanto, pela a corte não contar com muitos integrantes as denúncias por ela verificados são lentos porém ela é utilizada apenas como último recurso, inclusive um dos requisitos para que a denúncia seja aceita é exatamente esta que esgotem os meios legais do país antes que ela seja convocada.

Agora ao povo indígena Tapeba só resta uma opção que é aguardar, aguardar e resistir igual eles já o fazem a cerca de 500 anos, aguardar e resistir enquanto os não-índios tomam suas terras, proíbem sua língua, violam seus rios e lagos, os marginalizam e retiram seu direito à vida. Em razão disto este trabalho foi feito para trazer a atenção de seus leitores às questões indígenas, a demarcação não é uma simples questão civil para eles as terras dos povos indígenas é o que garante o direito a sua vida. Por isso é importante ressaltar a relevância de pesquisas no âmbito jurídico, para que se tenha mais clareza sobre os direitos constitucionais indígenas e as brechas existentes na legislação percebida nos desdobramentos dos processos de judicializações dos processos de demarcação de terras indígenas em situações específicas.A pesquisa aqui apresentada buscou evidenciar o processo de demarcação da Terra Indígena Tapeba, sendo este um primeiro trabalho que se mostrou um campo rico para aprofundamento em pesquisas futuras. 


\section{REFERÊNCIAS BIBLIOGRÁFICAS}

BARRETTO FILHO, Henyo T. Relatório de atividades do trabalho de campo realizado entre 01 de setembro de 2010 e 16 de maio de 2013 junto ao grupo étnico Tapeba em Caucaia, Ceará. Mimeo (Biblioteca do CDPDH da Pastoral Indigenista da Arquidiocese de Fortaleza). Maio de 2013.

. Tapebas, Tapebanos e Pernas-De-Pau de Caucaia, Ceará: da Etnogênese como Processo Social e Luta Simbólica. Dissertação de mestrado, Programa de Pós-Graduação em Antropologia Social do Museu Nacional, UFRJ. 1993.

BRASIL. Constituição (1988). Constituição da República Federativa do Brasil:

Promulgada em 5 de outubro de 1988. Disponível em:

<https://www2.senado.leg.br/bdsf/bitstream/handle/id/518231/CF88_Livro_EC91_2016.pdf>; Acesso em: 07 set. 2019.

Lei 6001 de 1973, de 19 de dezembro de 1973. Dispõe sobre o estatuto do índio. Disponível em: http://www.planalto.gov.br/ccivil_03/Leis/L6001.htm; Acesso: 07 SET. 2019.

BRASIL. MINISTÉRIO DA JUSTIÇA. Terras Indígenas. Brasília:DF. 2005.

Comissão Interamericana de Direitos Humanos, CONVENÇÃO AMERICANA SOBRE

DIREITOS HUMANOS, 22 de novembro de 1969, pode ser encontrado em

<https://www.cidh.oas.org/basicos/portugues/c.convencao_americana.htm>

CUNHA PORTO,

$<$ http://redir.stf.jus.br/paginadorpub/paginador.jsp?docTP=AC\&docID=603021\&pgI=286\&pgF=290

>. Mandado de Segurança nº 16.443, STF. Acesso em 10/09/2019.

DA SILVA, José Afonso. Curso de direito constitucional positivo. 24a ed., São Paulo: Malheiros, 2005.

FURTADO SOARES. Ana Aline. "TERRA DEMARCADA, VIDA GARANTIDA"

A (NÃO) DEMARCAÇÃO DA TERRA INDÍGENA TAPEBA. Monografia de graduação. Curso de Direito do Centro de Ciências Jurídicas da Universidade de Fortaleza. 19 de junho de 2009.

GALVÃO, Ilmar. Terras Indígenas In Doutrina STJ, Edição Comemorativa - 15 anos. Brasília, 2005.

SOUZA JUNIOR. Jose Alves. A COMPANHIA DE JESUS E A QUESTÃO DA ESCRAVIDÃO DE ÍNDIOS E NEGROS Artigo publicado na edição nº 55 de Agosto de 2012. Podendo ser encontrado em: http://www.historica.arquivoestado.sp.gov.br/materias/materia03/

STUART FILHO. Os Aborígenes do Ceará II. Revista do Instituto do Ceará (Fortaleza), v. 77, p.153-217, 1963. 
TERRAS INDÍGENAS. Portal. Acessado em <https://terrasindigenas.org.br/pt-br/terrasindigenas/3864>.

TÓFOLI, Ana Lúcia Farah de. As retomadas de terras na dinâmica territorial do povo indígena Tapeba [manuscrito]: mobilização étnica e apropriação espacial / por Ana Lúcia Farah de Tófoli. 2010. 